Document downloaded from:

http://hdl.handle.net/10251/106307

This paper must be cited as:

Albero Gabarda, V.; Saura Arnau, H.; Hospitaler Pérez, A.; Montalva Subirats, JM.; Romero, ML. (2018). Optimal design of prestressed concrete hollow core slabs taking into account its fire resistance. Advances in Engineering Software. 122:81-92.

doi:10.1016/j.advengsoft.2018.05.001

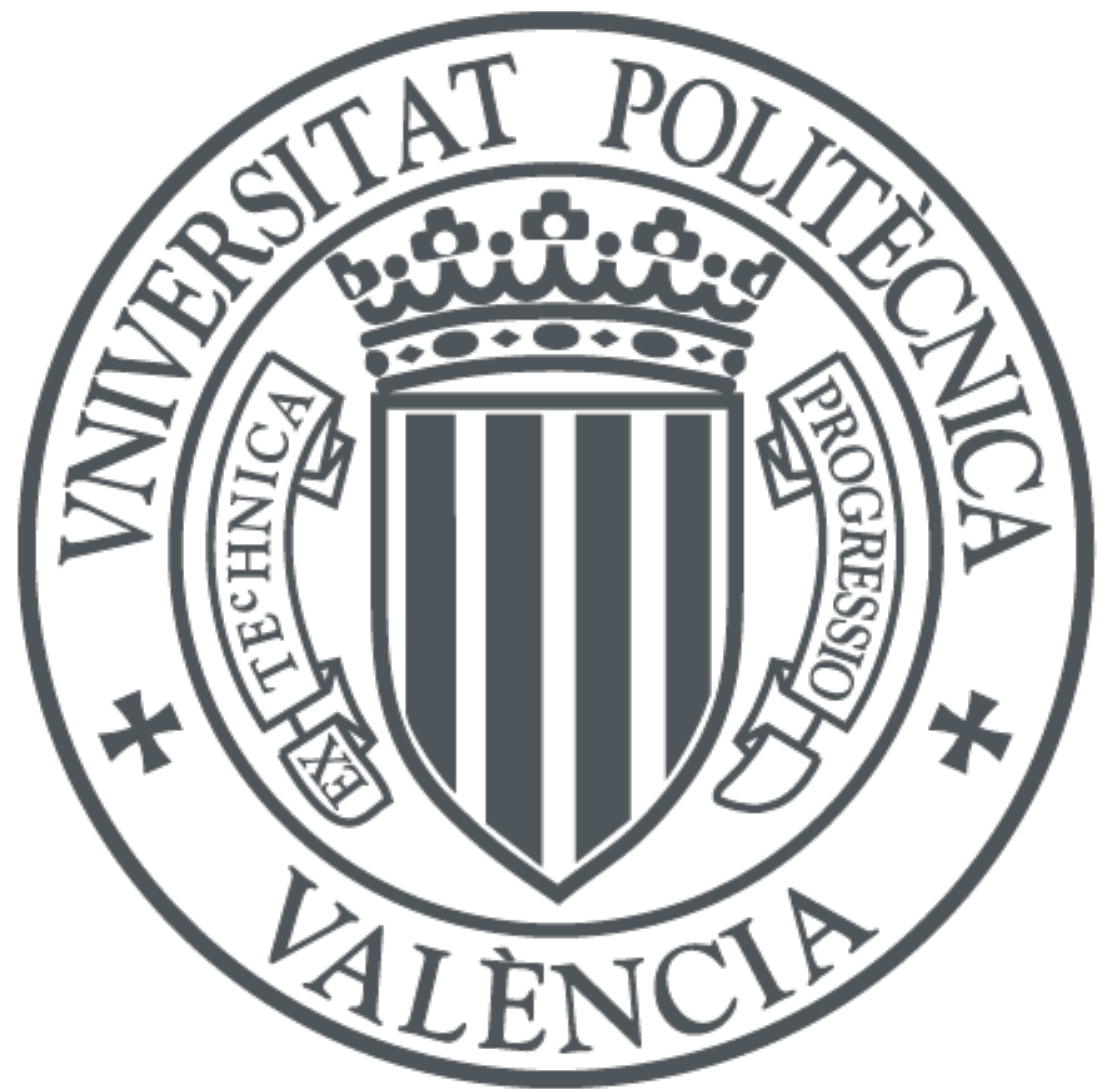

The final publication is available at

https://doi.org/10.1016/j.advengsoft.2018.05.001

Copyright Elsevier

Additional Information 


\title{
Optimal design of prestressed concrete hollow core slabs taking into account its fire behavior
}

\author{
V. Albero ${ }^{\mathrm{a}}$, H. Saura ${ }^{\mathrm{a}}$, A. Hospitaler ${ }^{\mathrm{a}^{*}}$, J. M. Montalvàa and Manuel L. Romero ${ }^{\mathrm{a}^{*}}$ \\ anstituto de Ciencia y Tecnología del Hormigón (ICITECH). \\ Universitat Politècnica de València, Spain.
}

\begin{abstract}
Prestressed hollow core slabs are a concrete element widely used as construction floor product, which manufacturing process has greatly been improved in recent years. Several research studies focused on hollow core slab performance, mainly related to its fire behavior, have provided new limit states to be assessed throughout its life cycle. Therefore, the hollow core slab design needs to be reviewed to allow for these improvements, a process which may involve changes to its geometry. In order to deal with this review, modern computational optimization techniques offer an alternative approach to traditional structural product design procedure, mainly based on the engineer's prior experience.

This paper proposes a hollow core slab model (including variables and constraints) to develop heuristic search algorithms, such as simulated annealing, in order to find the most economical slab design including the fire resistant constraint and taking into account all available manufacturing technologies. The optimal designs obtained by this process save up to $20 \%$ in cross-section area compared with common circular void designs from market, which is taken as a comparison pattern. The results show that traditional designs are deficient when the fire resistant constraint is considered, so that precast manufacturers and machinery designers should use optimization techniques to modify their hollow core slab geometry.
\end{abstract}

Keywords: structural optimization, fire resistance, hollow core slab, prestressed concrete 


\section{INTRODUCTION}

Precast prestressed hollow core concrete slabs are widely used to make floors in both residential and non-residential buildings and provides efficient structural behavior for long spans and high loads [1]. Furthermore, the estimated total stock of hollow core floors currently installed in Europe is 1.000 million square meters.

Since the early seventies, hollow core slabs have been thoroughly studied in research campaigns, in the USA [2], [3] and Europe [4] and many aspects of the product have been intensively tested, including its fire resistance [5],[6],[7]. Specific standards have been issued related to its structural behavior, including the PCI Manual for the design of hollow core slabs [8], FIB Special design considerations for precast prestressed hollow core floors [9] and the European product standard EN 1168 [10].

This type of slab is now widely used and its manufacturing process has been greatly improved to include strictly controlled design parameters. Specifically, hollow core slabs are manufactured in precast factories highly industrialized. The manufacturing process is to run the machines on steel beds up to $200 \mathrm{~m}$ long, equipped with stressing abutments where tendons are initially positioned and prestressed, see Figure 1a. These tendons may change in position, quantity and cross-section. The concrete casting is continuous and three specific procedures are available in the market: Slipformer, Extruder and Flowformer. The final geometry of the slab hollows is defined by a specific and interchangeable part of the casting machine called the finishing mold, see Figure 1b. This core mold can be replaced to manufacture different crosssection designs or slab heights. The slab wholes shape, quantity and position may change using the same machine but different finishing mold. Therefore, new proposals of hollow core slab designs may produce changes in this manufacturing finishing mold. 
Traditionally, engineers have relied on their experience to design structural products and so the same structural response could be achieved through diverse designs using different resources.

The current design of hollow core slabs is a forward design, which involves three steps. The first one is related to the machinery designer. In this step aspects as manufacturing procedure constraints or the fresh concrete consistency are used to design the finishing mold. Thus, many hollow core geometry designs appear in the market depending on the manufacturing process. This first step of the current hollow core slab design does not take into account any aspect of the final behavior of the slab in floors.

In the second step, the hollow core slab manufacturers cast the concrete slab with the available machinery but they only can change the concrete strength, the prestressed tendons position, quantity and tension. The slab geometry comes from the finishing mold, which was established in advance. The slab manufacturer are used to define some series of tendon configurations to offer different solutions reaching a specific range of bending capacity.

Finally, in the third step the floor project designer choose the proper configuration which provides enough mechanical capacity to the floor.

The forward design described above is clearly uncoupled. The mechanical requirements of the floor has no influence in the real hollow core slab geometry. Therefore, the current hollow core slab design procedure is strongly inefficient.

On the contrary, current computational optimization techniques offer another approach to deal with this problem. These techniques can manage all constraints, along the hollow core slab life cycle, together. Therefore, a real coupled design can be defined to provide optimal and efficient solutions. 
A wide range of structural concrete products, such as frames [11], [12], bridge piers [13], precast road bridges [14], road vaults [15], retaining walls [16] and foundations [17] have been studied from this approach using economic cost as the standard, although other factors like weight, environmental or constructability indicators have also been used.

The first study on precast hollow core floor optimization was carried out by Koskisto \& Ellingwood in 1997 [18]. The objective function defined was economic cost, including the cost of failure. This work used only four design variables and concluded that the slab height and reinforcement increment was an efficient way of improving maximum slab span and that concrete strength and reinforcement eccentricity were not significant. This work was focused only on bending capacity.

Noorzaei et al. [19] studied the optimal design of particular geometries of hollow core slabs as circular voids, normally produced by extrusion (spiroll manufacturing process) in Northern Europe and America. This work obtained the optimal depth of this slab type using bending moment as principal constraint.

More recent studies, such as Sgambi et al. [20], focused on the slab’s web design defined by five geometric variables, with weight as the objective function. This work only took into account the spalling stress constraint to avoid cracking in the web during manufacturing process. Specifically, this constraint is related to the transient design situation of prestress transfer.

Surprisingly, few studies have dealt with the optimal design of hollow core slabs and none has considered fire resistance in the optimization process and additional design constraints from manufacturing process.

Additionally, hollow core slab has now been greatly improved as regards its behavior in fires, due to catastrophic events like the Harbour Edge collapse in Rotterdam [21]. 
In 1999 premature collapse was observed in DIFT tests [22] in hollow core slabs, due to high temperatures, which was not deducible from the standards. This premature collapse was later analysed by van Acker [5] and Fontana \& Borgogno [6]. These studies defined a strain compatibility field in the cross-section due to a nonlinear temperature field, which caused stress in the webs. The premature collapse of the slab in fire tests could be explained by this undesirable web stress. However, subsequent studies [23], [24] concluded that this problem did not occur in floors with constrained longitudinal dilatation. Advanced finite element models have now been developed to reproduce this behavior [25], [26].

Traditionally, the fire resistant requirements are achieved in these slabs by adding prestressing steel and/or increasing the steel tendon concrete cover while maintaining the crosssection geometry. Choosing between these options is not always obvious. Besides, it has been observed that these approaches may provide an over capacity of bending moment resistance at room temperature and therefore, no efficient designs.

This paper therefore proposes a new approach with computational techniques and taking advantage of its controlled manufacturing process. A complete definition of the hollow core slab model is presented, including parameters, design variables, constraints and a cost-based objective function, including the fire resistance constraint and the models available to evaluate hollow core slabs at high temperatures. In this work, all of these constraints are added together taking into account all possible interactions.

Different optimal designs for 60 and 120 minutes of fire exposure were obtained. These fire exposure times are commonly used for residential and non-residential buildings. The optimal designs obtained are compared to determine the influence of fire resistance in the optimal crosssection geometry. All the limit states were considered during the complete hollow core slab life cycle, including the fire event. 


\section{OPTIMIZATION PROBLEM DEFINITION}

\subsection{Problem definition.}

In order to solve the disadvantages of the current uncoupled and inefficient design procedure of hollow core slabs, described previously, a new approach is presented. This is based on optimization techniques which allow to find an optimal design subject to all life cycle mechanical and geometrical constraints.

The problem of hollow core slab optimization involves a set of variables $\mathbf{x}=\left\{x_{i}\right\}$, related to cross-section geometry and materials, and an economic optimization to minimize the objective function:

$$
\min f(\mathbf{x})
$$

This optimization is subjected to inequality and equality constraints:

$$
\begin{array}{ll}
g_{j}(\mathbf{x}) \leq 0 & \mathrm{j}=1, \ldots, \mathrm{n} \\
h_{j}(\mathbf{x})=0 & \mathrm{j}=1, \ldots, m
\end{array}
$$

$X_{i} \in D_{i}$ where $D_{i}$ is the discrete variable domain of variable $i$.

$D_{i}=\left(d_{\mathrm{i} 1}, d_{\mathrm{i} 2}, \cdots, d_{i, q_{i}}\right) \quad i=1, \ldots, q_{i}$. Discrete Variable Design Problem (DVDP)

The set of all values (x) satisfying the constraints defines the feasible region $\mathrm{A}=\left\{\mathbf{x}: g_{j}(\mathbf{x}) \leq 0, h_{j}(\mathbf{x}) \leq 0, \forall j\right\}$ and any configuration $\mathbf{x} \in \mathrm{A}$ is a feasible solution of the problem.

Both, the objective function and the constraints depend on parameter (p) and design variable $(\mathbf{x})$ vectors.

The problem parameter vector $(\mathbf{p})$ is a subset of $(\mathbf{x})$ which contains all the remaining data necessary to compute a particular hollow core slab. These parameters are all magnitudes taken 
as fixed data throughout the optimization problem implementation, and their influence in the optimal design is not taken into account.

The aim of this discrete variable nonlinear optimization problem is to find a feasible solution with the lowest value of the objective function.

\subsection{Design variables and solution space.}

The design variables (x) are the magnitudes subject to variation during the optimization procedure. Their influence in the optimal design is studied and the best values are pointed out.

The main objective of this work is to include the influence of fire resistance in hollow core slab optimal design procedure, specifically focused on its geometry, so that the prestressing steel configuration and void geometry were defined as the main variables.

Three variable types were defined as follows (see Table 1):

- Cross-section geometry variables.

- Reinforcement geometry variables.

- Mechanical or material variables.

In the cross-section geometry variables the void is defined by 10 variables, see Figure 2 and Table 1. The void model introduced, which is related to the finishing mold, is able to reproduce any hollow configuration (Figure 3) and can be adapted to any manufacturing process (i.e. extruder, slipformer or flowformer).

The void curves were modelled as superellipse curves, where $a$ and $b$ are the semi-diameters of the curve:

$$
\left(\frac{x}{a}\right)^{k}+\left(\frac{y}{b}\right)^{k}=1
$$

The superellipse is adapted to concave or convex curves through the curve degree $(k)$, allowing different configurations, as shown in Figure 3. 
In order to complete the slab core definition an additional variable was established $\left(b_{w}\right)$ to determine the web thickness. This variable is closely related to the shear capacity of the slab and is mainly constrained by manufacturing technology and maximum aggregate dimension of the fresh concrete.

In the reinforcement geometry variables, some arrays were defined to fix the reinforcement quantity and position. In particular, the $\bar{y}_{i}$ array was defined to indicate the row coordinate from the lower edge and $\bar{\phi}_{i}$ defines the tendon diameter in each level. The amount of reinforcement is determined through the $[n]_{i j}$ matrix, where the tendon quantity is stored. Each matrix column refers to the slab web in which the tendon is placed. Additionally, $[n]_{i j}$ must be defined accurately in order to set symmetric prestressing force arrangements around the vertical axis.

Three mechanical/material variables were defined: concrete strength $f_{c k}$, prestressing steel strength $f_{p k}$ and initial prestressing stress $\sigma_{0}$.

The number of design variables considered in the solution space depends on the reinforcement framework and the slab void number. Working with seven reinforcement rows and five slab voids, the number of design variables reaches 48 . The set of value combinations for all variables may be defined as the solution space, which extends to $10^{25}$ due to combinatorial explosion and is impossible to explore in its entirety.

\subsection{Objective function.}

The objective function considered was the economic cost of the hollow core slab, defined as follows:

$$
f(\mathbf{x})=c_{c} \cdot A_{c}(\mathbf{x})+c_{s} A_{s}(\mathbf{x})
$$


The cost function depends on concrete cross-section area $\left(A_{c}\right)$, the amount of prestressing steel $\left(A_{s}\right)$, the concrete $\left(C_{c}\right)$ and steel $\left(C_{s}\right)$ unit price. These unit prices must include the different costs involved in the production process, such as transport, etc., as provided by de Castilho, et al. [27]. The unit prices obtained from Spanish hollow core manufacturers are shown in Table 2.

This cost objective function is the best index to provide information on the resources used in slab production. Other indexes (i.e. environmental indicators) can also be used but are outside the scope of this work.

\subsection{Constraints.}

\subsubsection{Implicit constraints.}

Any condition that the problem solution must satisfy in order to become a feasible solution was defined as a problem constraint.

The hollow core slab manufacturing process contains implicit constraints that were taken into account in the model, although they are not specifically described here and include: parallel top and bottom edge, equal shape for all slab voids, equal width of slab webs and symmetry of reinforcement arrangement around the vertical axis. The additional geometrical and structural constraints (not included implicitly) are shown below.

\subsubsection{Explicit constraints}

\section{a) Geometrical constraints}

The main explicit geometrical constraints are related to cross-section geometrical variables, defining the limits to web and flange thickness. They can be obtained from product standard EN 1168 [10] or EN 1992-1-1 [28]. Some other constraints from EN 1168 [10] on reinforcement 
position are established to complete the geometrical conditions, which are related to maximum and minimum distance between tendons, useful to avoid undesirable manufacturing cracks through the appropriate reinforcement distribution in the slab.

There are also some geometrical constraints, written as equality relations, called hardconstraints $(h(\mathbf{x})=0)$, which are necessary to link variables and parameters. Two void hardconstraints are defined:

$$
\begin{array}{ll}
h_{1}(\mathbf{x})=0 & h=h_{1}+c_{1}+h_{w}+c_{2}+h_{2} \\
h_{2}(\mathbf{x})=0 & 2 a_{2}=2 a_{1}+d
\end{array}
$$

Another was defined to link horizontal void variables with web thickness $\left(b_{w}\right)$ and void number $(n)$ :

$$
h_{3}(\mathbf{x})=0 \quad b=(n+1) b_{w}+2 n a_{2}+2 q_{6}
$$

b) Mechanical constraints at room temperature.

Apart from previous geometrical constraints, structural constraints were defined to check all the design situations throughout the slab life cycle [29] (see Table 3 and Figure 4). In this approach, the optimal design obtained will be useful for all design situations, taking all the limit states into account (Ultimate Limit States ULS and Serviceability Limit States SLS). These limit states will be checked even during transient design situations like transfer of prestress or accidental design situations, including fires. The model used to evaluate each limit state is provided by EN 1992-1-1[28] and EN 1168 [10].

Firstly, the transient design situation during transfer of prestress must be evaluated. In this situation the concrete still has not achieved its full strength and stresses must be kept lower than the limits recommended by the standards. The model for concrete strength development is obtained from EN 1992-1-1 [28]. Some models obtained from the regulations [30],[10] are used to avoid spalling, splitting and bursting, which may create undesirable cracks during 
production. Additional transient design situations are evaluated for the other construction steps, like transport or floor construction. The stress limits are checked again, taking into account the higher strength of the concrete, the new slab support conditions and the reinforcement prestress losses. All this stress states are checked through a fibre model developed specifically for the analysis of hollow core slabs in this work, see Figure 5.

Bending and shear ULS, deformation and crack control SLS were also included in the analysis (persistent design situations, see Table 3).

c) Fire resistance. Mechanical constraint.

This work includes an additional structural constraint related to the accidental fire design situation, which is one of its important contributions. This constraint of slab behavior in the fire situation can be used to find the best slab shape for fire resistance.

The structural fire design is one of the main topics of the field known as fire safety engineering, which follows the essential requirements of safety in case of fire. A fully analytical procedure for hollow core slab structural fire design is available to assess its performance in fire. This procedure requires three elements:

1. Fire model

2. Thermal model

3. Mechanical model at elevated temperatures.

In this work the standard curve ISO834 from EN 1363 [31] was the adopted as the fire model. This curve reduces the fire event for structural analysis to a heating curve, which can be used following EN 1991-1-2 [32] recommendations.

The second element in this procedure is a thermal model to evaluate the temperatures throughout the cross-section. EN 1168[10] Annex G provides a specific simplified thermal model for hollow core slabs and reduces computation times. 
The model defines level $a_{50 \%}$ as the cross-section level in which concrete width equals void width. It assumes a uniaxial temperature field, where the temperature of levels under $a_{50 \%}$ is obtained from EN 1992-1-2 [33] Figure A.2 for solid slabs. Additionally, a linear interpolation is used between $a_{50 \%}$ and the unexposed upper edge at $160{ }^{\circ} \mathrm{C}$.

A cross-section temperature field obtained following the thermal model explained above is shown in Figure 6 for a hollow core slab exposed to an ISO834 curve for 60 and 120 minutes (R60-R120).

The third element is related to the mechanical model at high temperatures. Bending and shear models are available in the standards. In this work the $500^{\circ} \mathrm{C}$ isotherm method from EN 19921-2[33] Annex B was used for assessing bending in fires. This is a simplified calculation method applicable to a standard fire exposure based on a reduction of cross-section size. Concrete at temperatures in excess of $500^{\circ} \mathrm{C}$ is assumed not to contribute to load bearing, while residual concrete (temperatures lower than $500{ }^{\circ} \mathrm{C}$ ) retains its full strength and elasticity. On the other hand, the reinforcement strength is reduced due to temperature, according to EN 1992-1-2 [33] Clause 4.2.4.3, assuming that the prestressing steel temperature matches the surrounding concrete.

EN 1168 [10] provides a specific model for hollow core slabs for shear behavior at high temperatures:

$$
V_{R d, c, f i}=\left[C_{\theta .1}+\alpha_{k} C_{\theta .2}\right] b_{w} d
$$

Where $C_{\theta .1}$ is a coefficient that takes into account high-temperature concrete stress, $C_{\theta .2}$ is related to reinforcement anchorage in fires, $\alpha_{k}=1+(200 / d)^{1 / 2} \ngtr 2$ and $d$ is the effective depth of the slab. 


\subsubsection{Tie of mechanical constraints.}

All the structural constraints, defined in 2.4.2, to verify hollow core slab behavior throughout its lifecycle are tied to ensure that the optimal design could be used for any design situation. Therefore, they are not independent and are linked through the load pattern and boundary conditions established in the project.

Traditionally, the optimization of hollow core slabs has focused on the verification of the main structural constraint due to bending $[18,19]$. However, as explained above, multiple constraints, classified into limit states, have now been added to the standards. Through the traditional approach, optimal design could be reached ensuring a safety factor for ULS bending higher than 1.00. Nevertheless, it does not take into account other design situations such as ULS shear, SLS deflection or accidental fires. Figure 7a shows the safety factor for all limit states of an optimal hollow core design obtained through the methodology described in this work when only bending approach is taken into account. It can be seen that while ULS bending shows a safety factor value 1.00 others as ULS bending and shear in fire result to unsafe behavior with value 0.27 and 0.47 respectively. It shows that other approach is needed where all design situations would be taken into account.

Therefore, in the present work, in order to verify all the limits states together, they were tied through two conditions:

- $\quad$ Pinned-Pinned boundary condition.

- Uniform load distribution.

Using these conditions and the slab span and load amplitude, which are established as parameters in section 4, design values for all bending and shear design situations $\left(M_{E d}, V_{E d}, e t c.\right)$ can be obtained coordinately. Figure $7 \mathrm{~b}$ shows the safety factor results for a hollow core design following this new approach. As all reach values higher than 1.00, all the 
limit states are verified, in contrast with results shown in Figure 7a. It is also shown in Figure 7b that ULS Bending, SLS Deflection and ULS Bending in fires obtain the safety factor value closest to 1.00, which indicates that the most important constraints are related to these limit states, therefore they have the highest influence in the hollow core slab design.

\section{APPLIED HEURISTIC SEARCH METHODS}

Combinatorial optimization problems like the one described here can require a huge solution space, as has been pointed out in Section 2.2 (e.g. $10^{25}$ solution space). The analysis of the entire solution space is a difficult task, even with the large computational capacity now available. However, approximation algorithms (i.e. heuristic methods) are available to explore the most promising space solution areas and can reach an approximate solution in an acceptable time. The simulated annealing algorithm, proposed by Kirkpatrick et al. [34] and Cerny [35] was selected for the analysis. This algorithm is based on randomization techniques and also includes aspects related to iterative improvement. The simulated annealing application focuses on a small perturbation to generate the transition from one configuration to another. This perturbation defines a neighbourhood for each configuration, consisting of all the configurations that can be reached from the previous one, so that it can be classified as a search algorithm. However, unlike other search techniques, simulated annealing incorporates a probabilistic acceptance criterion, i.e. a perturbation may be accepted even when the feasible solution reached does not improve the objective function. The probabilistic acceptance criterion is defined following the Boltzmann distribution:

$$
p=\min \left(1 ; e^{\frac{-\Delta E}{T}}\right)
$$

Where $p$ denotes the probabilistic acceptance between $(0,1)$ interval; $\Delta E$ is the objective function variation due to the perturbation and $T$ is a control parameter called "temperature”. It 
is worth noting that this control parameter has no relation with the fire resistant constraint because it has no physical meaning. In the first steps of the application, "temperature" is initiated with a high value providing high probabilistic acceptance for solutions which do not improve the objective function. The "temperature" is gradually reduced throughout the execution and the probabilistic acceptance also diminishes. In the final steps only the best solutions are accepted and local optimal solutions are avoided. The simulated annealing implementation requires a cooling schedule to guide the control parameter "temperature" (van Laarhoven P.J.M and Aarts E.H.L [36]). This cooling schedule should be specifically calibrated for each problem. In the present analysis the initial "temperature" was set to provide an initial probabilistic acceptance of $90 \%$ and was reduced as follows, established in steps of 10.000 perturbations (also called the “Markov chain”):

$$
T_{i+1}=0.95 T_{i}
$$

The algorithm stops when 50.000 perturbations have been analyzed consecutively without any improvement.

\section{OPTIMIZATION RESULTS}

The optimization algorithm described above was applied to the developed hollow core model. The optimal design was focused on a $25 \mathrm{~cm}$ high and $120 \mathrm{~cm}$ of width hollow core slab with 5 voids. This study is focused in the hollow core slab geometry, thus the influence of concrete topping $\left(h_{0}=0\right)$ was neglected.

The boundary and load conditions were established as follows:

- $\quad$ Pinned-Pinned boundary conditions.

- Total span: $8 \mathrm{~m}$.

- Dead load: $\mathrm{G}=2 \mathrm{kN} / \mathrm{m}^{2}$. Live load: $\mathrm{Q}=5 \mathrm{kN} / \mathrm{m}^{2}$. 
Additional conditions were defined by the remaining structural constraints. For concrete building interiors with moderate humidity or external concrete sheltered from rain, the XC3 of the exposure class from EN 1992-1-1 [28] was set for SLS crack control. The following deflection limit $\left(w_{\max }\right)$ for SLS deflection design situation was defined according to total span $(L)$ :

$$
w_{\max }=\min \left\{\frac{L}{250} ; 0.01+\frac{L}{500}\right\}
$$

As we focus on the optimal design of void geometry, the variables related to material properties, lateral joint geometry and reinforcement system were fixed as parameters.

- $\quad$ Lateral joint geometry (q) is defined through 7 parameters (see Figure 8).

$$
\mathbf{q}=\left\{q_{i}\right\}=\{40,35,137.5,15,22.5,33.5,12\} \mathrm{mm}
$$

- Concrete cylinder strength: $f_{c k}=45 \mathrm{MPa}$.

- $\quad$ Maximum reinforcing steel strength: $f_{p k}=1860 \mathrm{MPa}$.

- Initial prestressing stress: $\sigma_{0}=1324 \mathrm{MPa}$.

- $\quad$ The reinforcement arrangement is placed in 7 rows $(i=7)$.

- $\quad$ Reinforcement diameter for all rows $\phi_{i}=5 \mathrm{~mm}$ (Y $\left.1860 \mathrm{C}\right)$.

The optimization results are shown in Figure 9 and Table 4.

The algorithm was submitted using two different fire resistant times, in order to compare their optimal designs. Figure 9c shows the optimal design obtained at 60 minutes of fire exposure (R60), which is habitual in residential buildings. Figure 9d shows the optimal design for 120 minutes of fire resistance (R120), which can be used for industrial and commercial floors.

Contrary to expectations, significant differences were observed (see Figure 9c and Figure 9d). While the upper void edge design did not show appreciable differences, the lower side (C)2018. This manuscript version is made available under the CC-BY-NC-ND 4.0 license https://creativecommons.org/licenses/by-nc-nd/4.0/ 
obtained by each submission was quite different. The R60 analysis reached the usual concave curvature in the void lower edge. However, for a higher fire resistance time (R120), convex curvature was the most economical geometry to deal with all the constraints, which indicates that this curvature change is due to the fire constraint. Improved hollow core fire resistance can be obtained by separating the rebars from the lower fire-exposed surface, although the minimum concrete cover between the lower and void edges should be maintained. When the rebars are moved upwards towards the web in order to increase fire resistance, the convex lower void edge appears to be the most economical geometry with the minimum amount of concrete.

Additionally, a hollow core design with circular voids, which worked as a market pattern, was also computed (see Figure 9a and Figure 9b) to be compared with the optimal designs obtained. This specific design was verified using the same constraints as the optimal designs, including R60 and R120 fire exposure, and may be considered as a common market design of hollow core slabs. In fact, circular voids are very common in the extruder casting procedure.

Table 4 compares the numerical results of the optimal designs with this market pattern. A total saving of $24 \%$ in terms of cross-section area was achieved in R60 optimal design, while the R120 optimal design reduced cross-section by $19 \%$. This reduction is related to the economic saving of the optimal designs and shows that an optimal hollow core slab and considerable savings can be achieved by the proposed model and algorithm. A $5 \%$ difference in cross-sectional area was observed when the fire constraint was increased from R60 to R120.

\section{THERMAL MODEL INFLUENCE. LOCAL SEARCH IMPROVEMENT}

One of the main assumptions of this design procedure is related to the thermal model that evaluates the temperatures within the hollow core slab cross-section during fires, described in Section 2.4.2c. The thermal model used in the optimal design procedure is a simplistic proposal provided by EN 1168 Annex G [10], which assumes a uniaxial temperature field .The 
temperature of levels under $a_{50 \%}$ is obtained from EN 1992-1-2 [33] Figure A.2 for solid slabs and a linear interpolation between level $a_{50 \%}$ and the unexposed upper edge at $160^{\circ} \mathrm{C}$ is proposed (see Figure 6). This simplistic model allows obtaining a temperature field with low computational cost, which permits an efficient algorithm performance.

The tied optimization showed that one of the main limit states, which define the obtained optimal design, is ULS Bending in fire (safety factor $=1.00$ ) (see Figure 7b). Since the thermal model is the most important influence on ULS Bending in fire an analysis was carried out on this assumption.

In order to assess the robustness of the solution achieved, the simplistic proposal from EN 1168 Annex G [10] was compared with an advanced finite element model (FEM) previously developed by the authors [26]. This finite element model deals with a nonlinear heat transfer problem, where EN 1991-1-2 [32] governing parameters were adopted and EN 1992-1-2 [33] recommended values were used for the concrete and steel temperature dependent thermal properties. This model was previously validated against an experimental campaign [37] and showed a good fitting. Besides, it may be highlighted the cavity radiation model for the thermal evolution in holes.

The optimal design obtained for R120 (Figure 9d) was processed by the advanced thermal FE model and a new temperature field was obtained (see Figure 10 and Figure 11).

Figure 10 and Figure 11 show that the simplistic proposal from EN 1168 Annex G provides higher temperatures for the lower edge of the cross-section but underestimates the temperature of the cross-section fibres placed 25-55 mm from the lower edge. This position, where the simplistic proposal obtains lower temperatures, is where the main bending steel reinforcement is usually placed. Therefore, the simplistic thermal model from EN 1168 Annex G does not provide safer predictions than the advanced thermal model. Indeed, using the advanced FE 
thermal model the bending resistance for the optimal design in fire is reduced by up to $20 \%$. Figure 12 shows that a temperature variation of approximately $100^{\circ} \mathrm{C}$ in the steel reinforcement considerably reduces tendon strength.

Figure 10 also shows that the $160^{\circ} \mathrm{C}$ prediction for the unexposed upper edge from the EN 1168 simplistic thermal model should by reviewed for fire resistance times below 60 minutes.

Consequently, the thermal model variation causes moderate differences in bending resistance in fires. Therefore, the optimization process was resubmitted using the advanced FE thermal model. This new procedure, with high computational cost, was applied to the previously obtained optimal R120 solution up to reach convergence. Specifically, it consist of a local search improvement maintaining the field temperatures from FEM thermal model after each local search. The modified cross-section design obtained using the advance FEM is shown in Figure 13.

This new optimal design maintains lower void convex curvature, but the web thickness of the bottom part is too small due to the temperature increment from the thermal model. The reinforcement concrete cover on the bottom edge was increased and only one tendon was placed in each position for lower reinforcement eccentricity. Therefore, the reinforcement needed to be increased $(+16.7 \%)$ in order to maintain bending resistance. This new optimal design has a smaller concrete cross-section $(-2.2 \%)$ but greater reinforcement $(+16.7 \%)$ and the economic cost is approximately the same as the original optimal design for R120 (see Table 5).

\section{SENSITIVITY ANALYSIS}

After obtaining the optimal designs, a sensitivity analysis was carried out to check their robustness by the uncertainty of the input assumptions of material unit prices, concrete strength and reinforcement system. 


\subsection{Uncertainty of material prices}

The material prices are introduced in the objective function, which was defined as a linear function. Consequently, linear variations in the unit prices did not provide any change in the results obtained. The variation of the material price ratio (steel/concrete) was studied (see Table 6). The initial price ratio was 18.8 (price of steel over concrete).and was modified to 16.9 (10\%) and $20.7(+10 \%)$. When the algorithm was resubmitted the optimal design did not change significantly. Indeed, the cross-section area underwent a variation of less than $1.3 \%$ and the main variables of flange and web thickness remained constant.

It was therefore seen that the optimal design reached is sufficiently robust, even when material price ratio uncertainty is included.

\subsection{Concrete strength}

The analysis of concrete strength variation (see Table 6) shows that the optimal designs obtained from the algorithm (using different concrete grades) did not cause significant changes and the cross-section area variation was less than $1.63 \%$.

It can therefore be concluded that the optimal design did not undergo significant changes when concrete strength was modified.

\subsection{Prestressing steel system}

One of the parameters fixed in the optimization carried out was related to the configuration of the reinforcement; following the common practice in Spain only wires (Y 1860 C $\phi 5$ ) were used for reinforcement. However, 3/8'’ strands (Y 1860 S7) may also be when higher bending moments are required. In order to analyze the influence of the reinforcement system on slab geometry, the optimization process was resubmitted with 3/8'" strands for the lower 
reinforcement. The results obtained showed that this reinforcement reduced the concrete crosssection of the hollow core slab by only $1.5 \%$ (see Table 6 ).

\section{CONCLUSIONS}

The results obtained show that an optimal design of precast hollow core slab could be achieved by the proposed model and heuristic algorithm. The optimal design obtained approximately $20 \%$ savings in cross-sectional area over common market circular void hollow core slab.

With regard to the main objective of this work, the fire resistant constraint was shown to have a strong influence on the optimal hollow core slab design, as significant differences were obtained for R60 and R120 fire resistance times. The slab void with lower edge convex curvature was found to be the most economic design for higher fire resistance and increased reinforcement concrete cover of the lower slab edge, which is commonly exposed to fires. It also uses the minimum amount of concrete to cover the wires from the slab voids.

The sensitivity analysis showed the optimal design to be robust when input parameter uncertainties were added, such as material prices, concrete grade and reinforcement configuration. However, as the thermal model analysis showed that it causes significant differences in bending resistance in fire and in its optimal design, this means that the thermal hollow core slab model needs further study.

This work has thus shown that the current hollow core slab design is not optimal when the fire resistant constraint is taken into account. As a consequence, precast manufacturers should modify their designs for high fire resistance using convex curvature in the lower void edge. 


\section{REFERENCES}

[1] IPHA. International Prestressed Hollowcore Association. www.hollowcore.org. 2016.

[2] Scott NL. Performance of precast prestressed hollow core slab with composite concrete topping. PCI Journal. 1973.

[3] Becker RJ, Buettner DR. Shear test of extruded hollow core slabs. PCI Journal. 1985.

[4] Walraven J, Mercx W. The bearing capacity of prestressed hollow core slabs. HERON. $1983 ; 28$.

[5] Van Acker A. Sher resistance of prestressed hollow core floors exposed to fire. Structural Concrete. 2003;4:65-72.

[6] Fontana M, Borgogno W. Structural Behaviour of Slim Floor Slabs with Prestressed Hollow Core Elements at Room Temperature and in Fire. Composite Construction in Steel and Concrete2000. p. 768-79.

[7] Jansze W, Van Acker A, Della Bella B, Klein-Holte R, Linström G, Py J-P et al. Structural behaviour of prestressed concrete hollow core floors exposed to fire. 2014. p. 226.

[8] PCI. Manual for the design of hollow core slabs. Chicago: PCI, Precast Prestressed Concrete Institute; 1998.

[9] CEB-FIB. Special design considerations for precast prestressed hollow core floors: FIB Comission 6 - Prefabrication; 2000.

[10] EN-1168:2005+A3:2011. Precast concrete products. Hollow core slabs. Brussels, Belgium: CEN; 2011.

[11] Payá I, Yepes V, González-Vidosa F, Hospitaler A. Multiobjective optimization of reinforced concrete building frames by simulated annealing. Computer-Aided Civil and Infrastructure Engineering,. 2008;23:575-90.

[12] Esfandiari MJ, Urgessa GS, Sheikholarefin S, Manshadi SHD. Optimum design of 3D reinforced concrete frames using DMPSO algorithm. Advances in Engineering Software. 2018;115:149-60.

[13] Martínez FJ, González-Vidosa F, Hospitaler A, Yepes V. Multi-objective optimization design of bridge piers with hybrid heuristic algorithms. Journal of Zhejiang University. 2012;13:420-32.

[14] Martí JV, Gonzalez-Vidosa F, Yepes V, Alcalá J. Design of prestressed concrete precast road bridges with hybrid simulated annealing. Engineering Structures. 2013;48:342-52.

[15] Carbonell A, González-Vidosa F, Yepes V. Design of reinforced concrete road vaults by heuristic optimization. Advances in Engineering Software. 2011;42:151-9.

[16] Yepes V, Gonzalez-Vidosa F, Alcala J, Villalba P. CO 2-optimization design of reinforced concrete retaining walls based on a VNS-threshold acceptance strategy. Journal of Computing in Civil Engineering. 2012;26:378-86.

[17] Camp CV, Assadollahi A. CO2 and cost optimization of reinforced concrete footings using a hybrid big bang-big crunch algorithm. Structural and Multidisciplinary Optimization. 2013;48:411-26.

[18] Koskisto OJ, Ellingwood BR. Reliability-based optimization of plant precast concrete structures. Journal of Structural Engineering. 1997;123.

[19] Noorzaei J, Wong JN, Thanoon WA, Jaafar MS. Software Development for Optimal Design of Different Precast Slabs. Pertanika J Sci \& Technol. 2009;17:69-85.

[20] Sgambi L, Catallo L, Bontempi F. Genetic algorithm optimization of precast hollow core slabs. Computers and Concrete. 2014;13:389-409.

[21] Van Overbeek T, Breunese A, Gijsbers J, Both K, Maljaars J, Noordijk L. New regulations for hollow core slabs after premature partial collapse. 2010. p. 141-8. 
[22] Andersen N, Lauridsen M. Danish Institute of Fire Technology - Technical Repor X 52650 Part 2 - Hollow core concrete slabs. 1999.

[23] Lennon T. Precast Concrete Hollow Core Slabs in Fire. The Structural Engineer. 2003;81:30-5.

[24] Bailey CG, Lennon T. Full-scale fire tests on hollowcore floors. Structural Engineer. 2008;86:33-9.

[25] Kodur VKR, Shakya AM. Modeling the response of precast, prestressed concrete hollow-core slabs exposed to fire. PCI Journal. 2014;59:78-94.

[26] Aguado JV, Albero V, Espinos A, Hospitaler A, Romero ML. A 3D finite element model for predicting the fire behavior of hollow-core slabs. Engineering Structures. 2016;108:12-27.

[27] de Castilho VC, Nicoletti MC, El Debs MK. An investigation of the use of three selection-based genetic algorithm families when minimizing the production cost of hollow core slabs. Computer Methods in Applied Mechanics and Engineering. 2005;194:4651-67.

[28] CEN. EN 1992-1-1, Eurocode 2: Design of concrete structures. Part 1-1: General rules and rules for buildings. Brussels, Belgium: Comité Européen de Normalisation; 2004.

[29] Elliot KS. Precast Concrete Structures: CRC Press; 2002.

[30] FIP. Precast prestressed hollow core floors: Telford; 1988.

[31] CEN. EN 1363-1:2012 Fire resistance tests. General Requirements. Brussels, Belgium: Comité Européen de Normalisation; 2012.

[32] CEN. EN 1991-1-2, Eurocode 1: Actions on structures. Part 1-2. General actions actions on structures exposed to fire. Brussels, Belgium: Comité Européen de Normalisation; 2002.

[33] CEN. EN 1992-1-2, Eurocode 2: Design of concrete structures. Part 1-2: General rules - Structural fire design. Brussels, Belgium: Comité Européen de Normalisation; 2004.

[34] Kirkpatrick S, Gelatt CD, Vecchi MP. Optimization by Simulated Annealing. Science. 1983;220:671-80.

[35] Cerny V. Thermodynamical approach to the traveling salesman problem - An efficient simulation algorithm. J Optim Theory Appl. 1985;45:41-51.

[36] Laarhoven van PJM, Aart EHL. Simulated annealing Theory and applications: Kluwer Academic Publishers; 1988.

[37] Aguado JV, Espinos A, Hospitaler A, Ortega J, Romero ML. Influence of reinforcement arrangement in flexural fire behavior of hollow core slabs. Fire Safety Journal. 2012;53:72-84. 




a) Casting beds

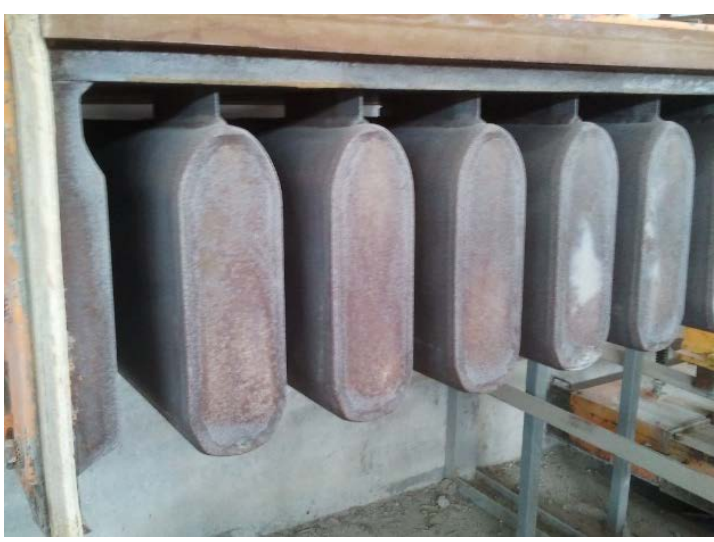

b) Finishing mold

Figure 1. Hollow core slab, manufacturing process. (Manufacturer pictures: HORVITEN S.L \& HERMO S.L, Spain). 


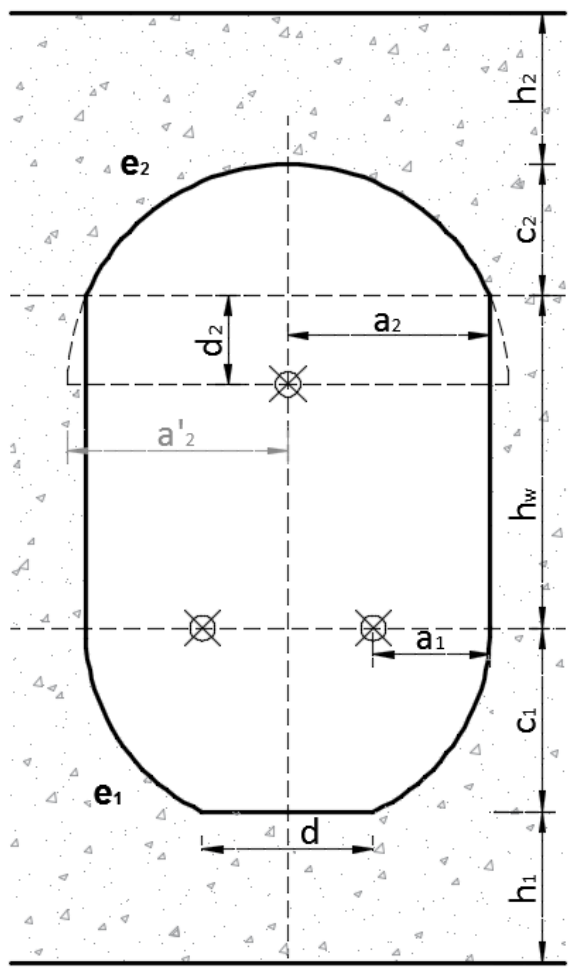

Figure 2. Void model (10 variables) 


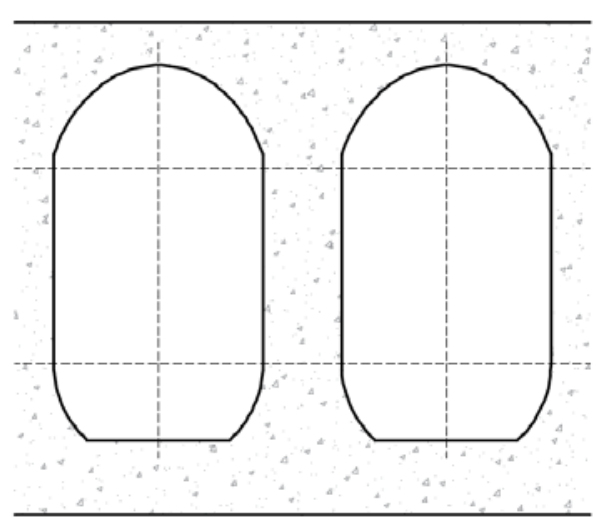

a) Generic void a

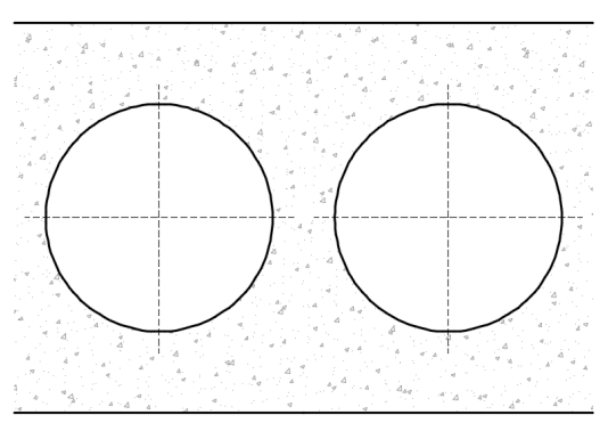

c) Circular voids



d) "Pill" void

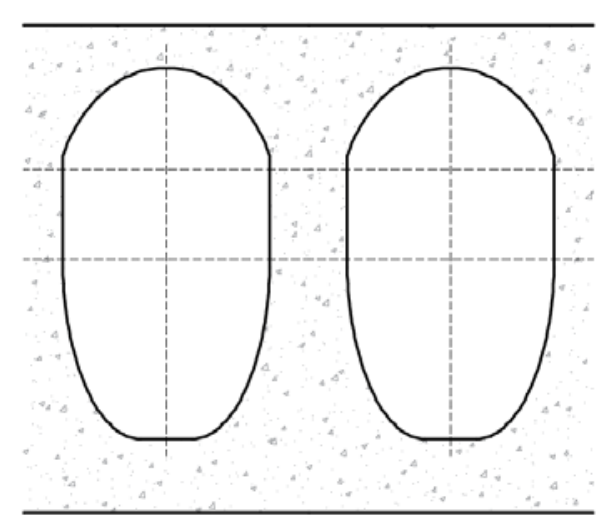

b) Generic void b
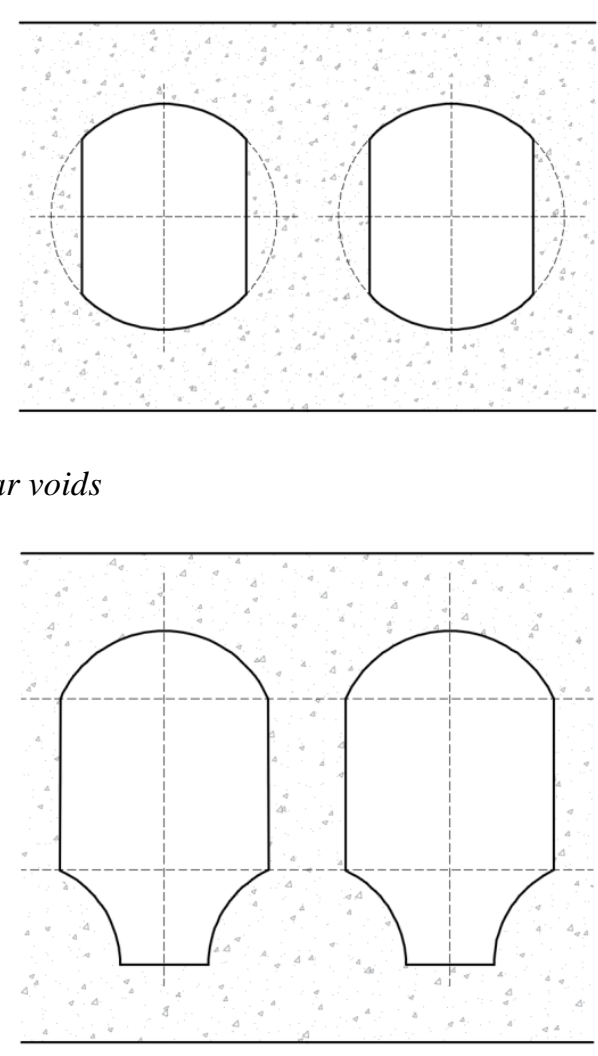

e) “Cup” void

Figure 3. Void model adaptability 


\section{Hollow core slab - Lyfecycle}
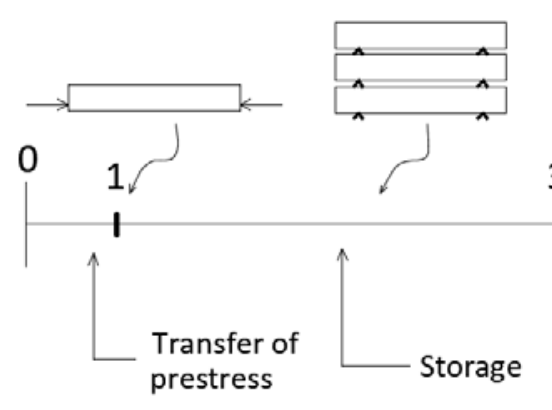

Transient design situations q

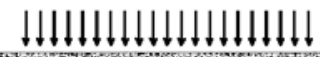

30

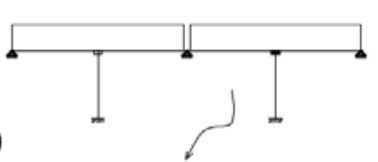

$\mathrm{x}$

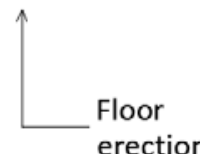

Floor
erection

Floor

service

Persistent \& accidental design situations

Figure 4. Hollow core slab lifecycle. 

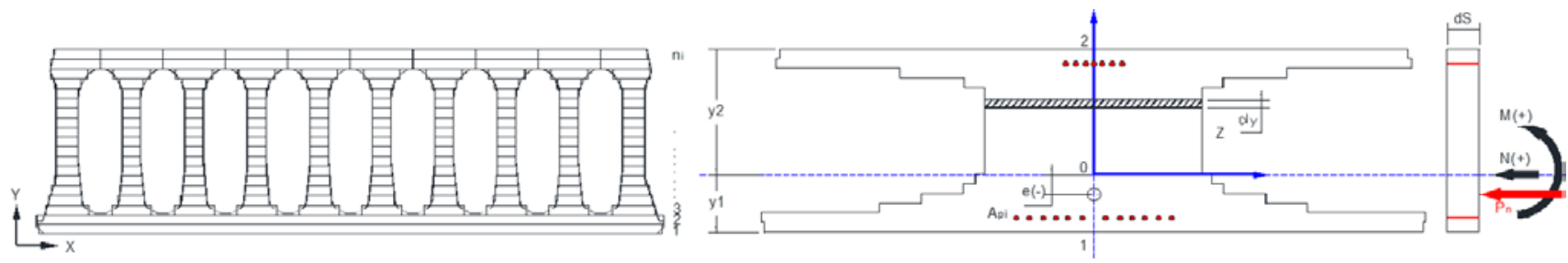

Figure 5. Fibre model for hollow core stress analysis 



Figure 6. Hollow core slab EN 1168 simplified thermal model 
a)

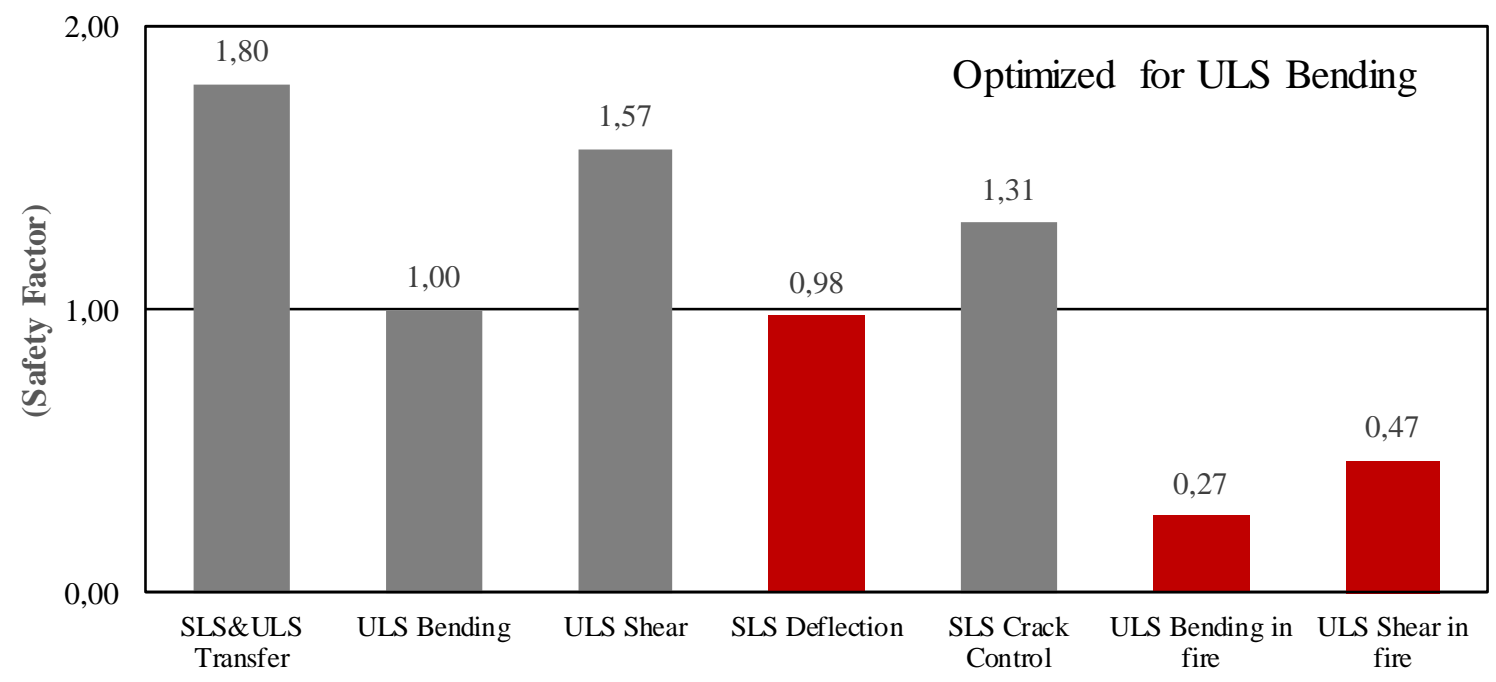

b)

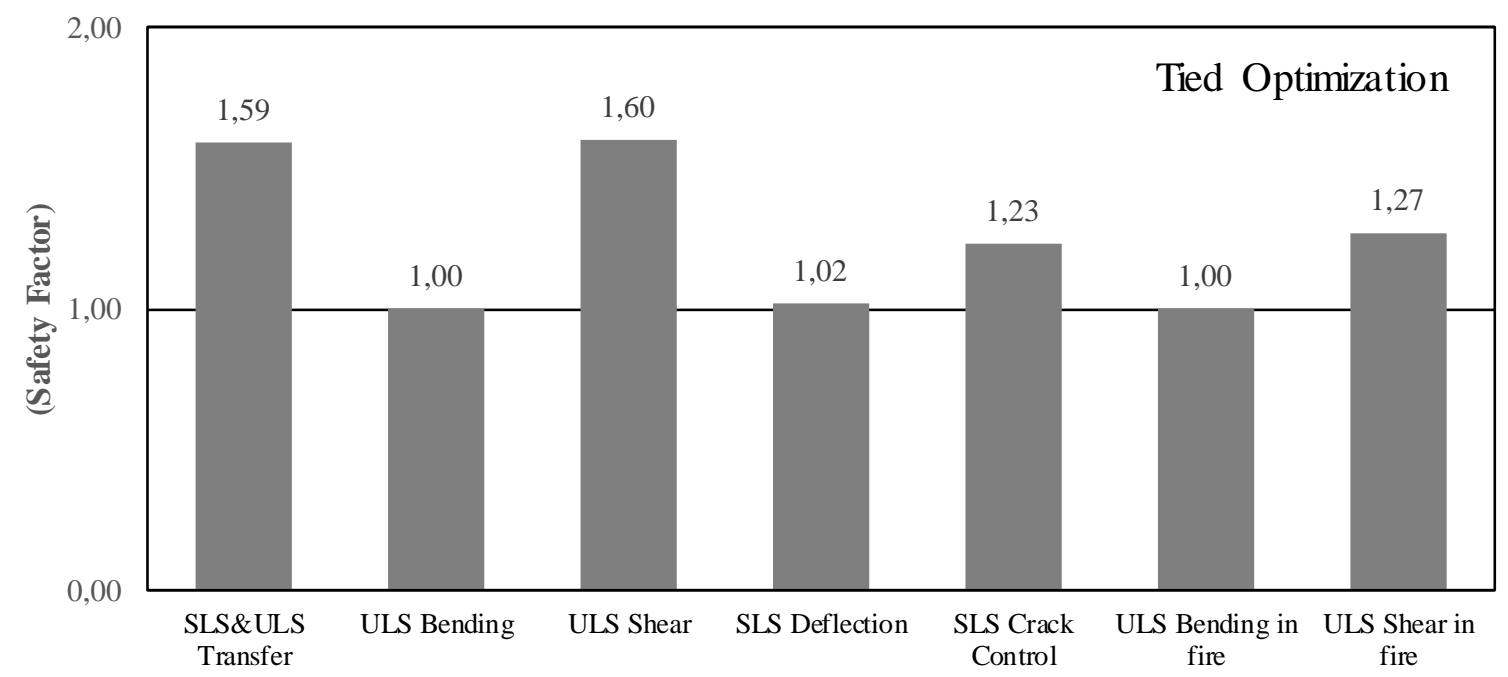

Figure 7. Safety factor: a) Untied optimization; b) Tied optimization. 


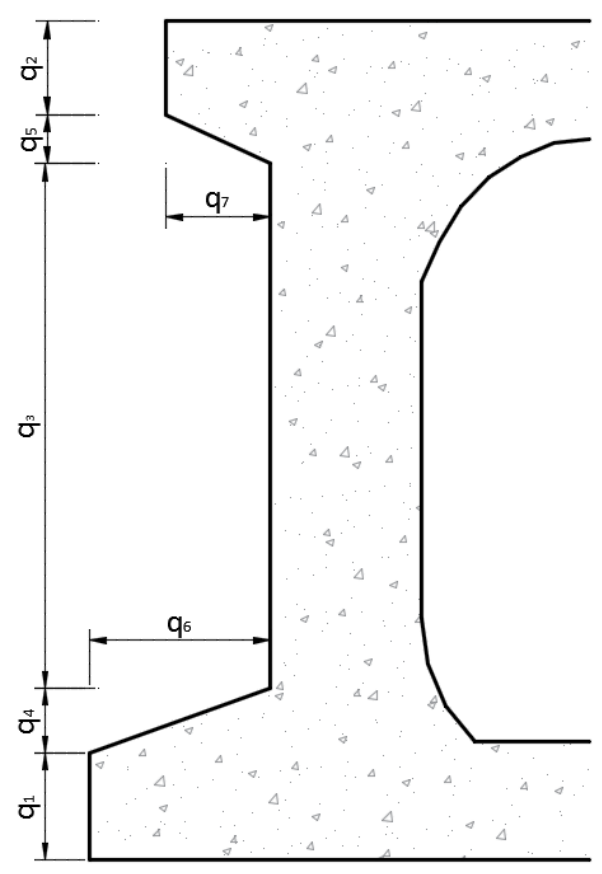

Figure 8. Lateral joint model (7 parameters) 


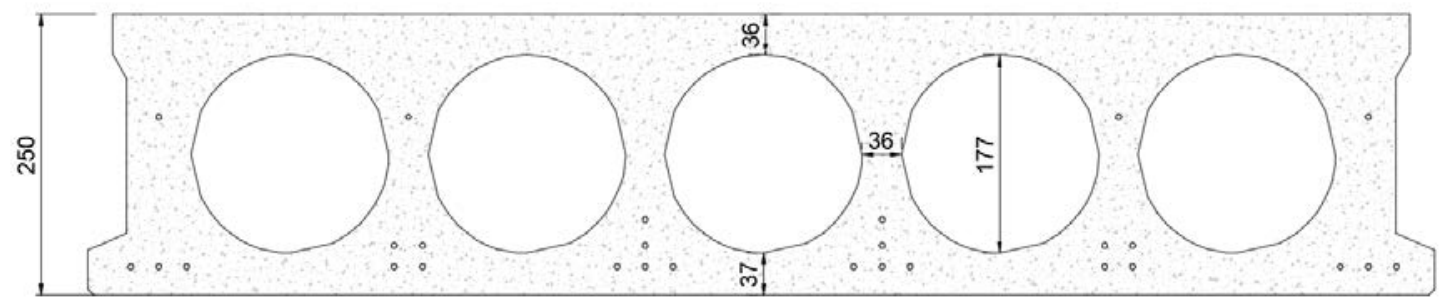

a) Circular voids (pattern) R60

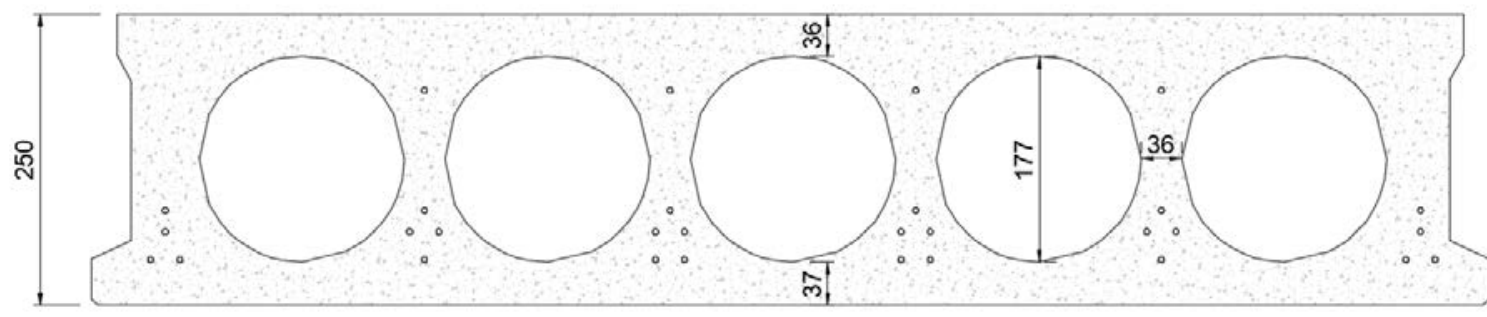

b) Circular voids (pattern) R120



c) Optimal design R60

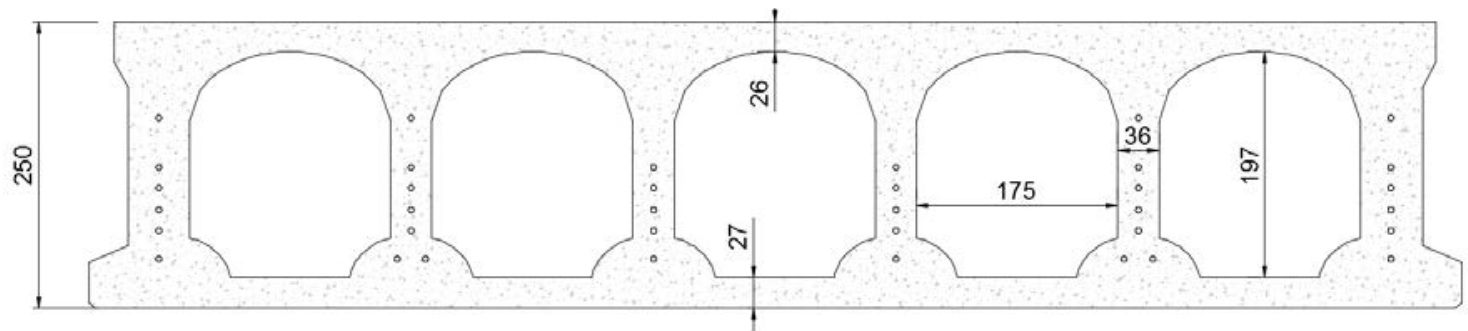

d) Optimal design R120

Figure 9. Optimal designs 


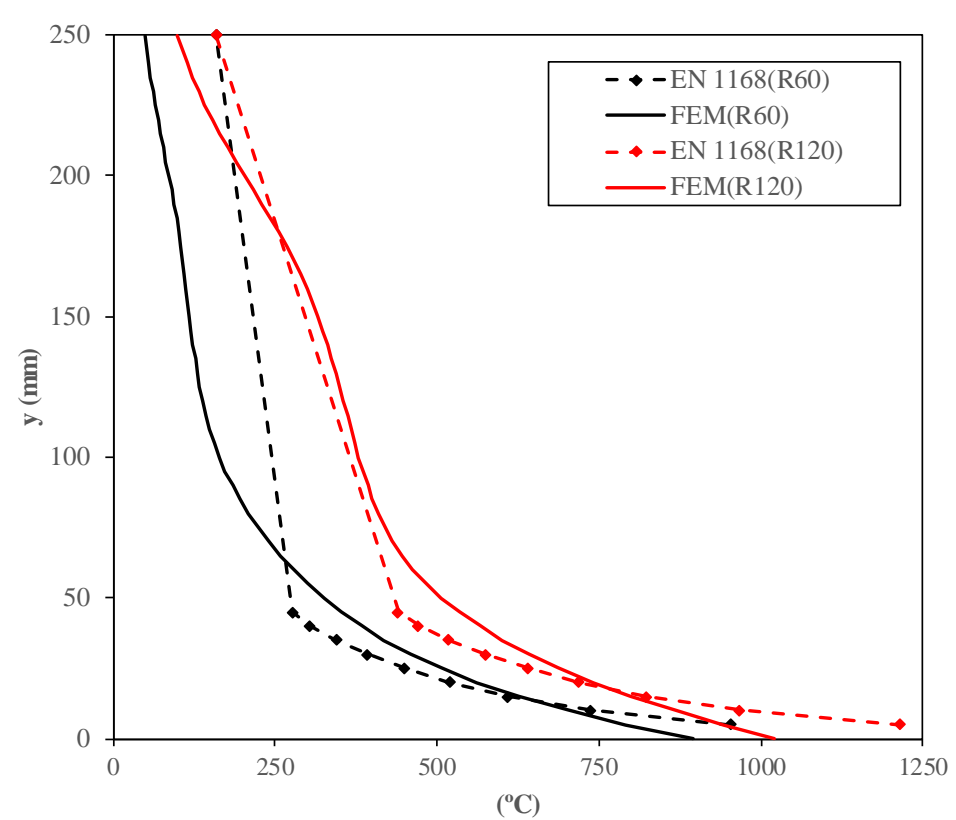

Figure 10. Temperature comparison for optimal design R120 

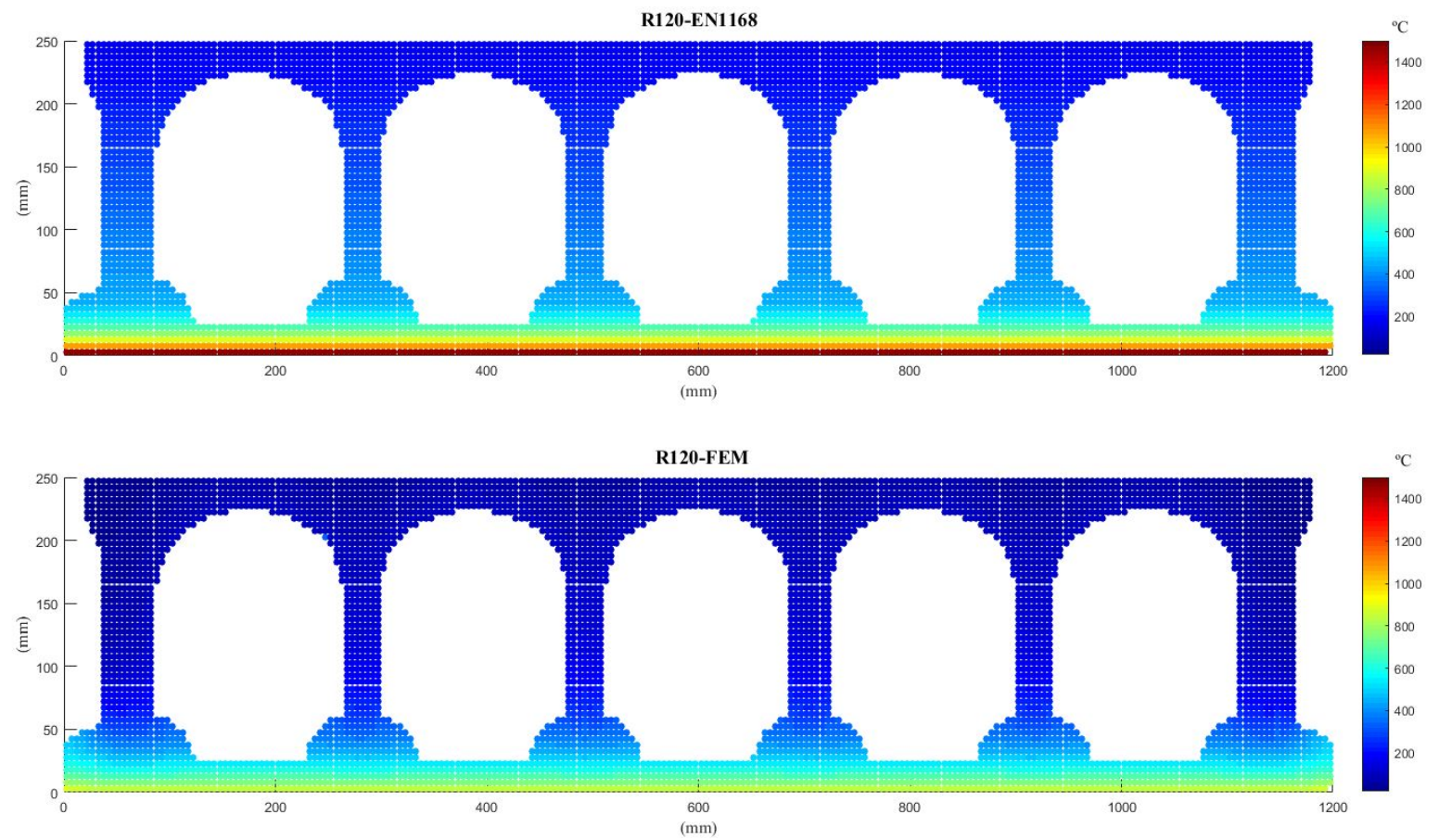

Figure 11. Temperature field comparison for optimal design R120 


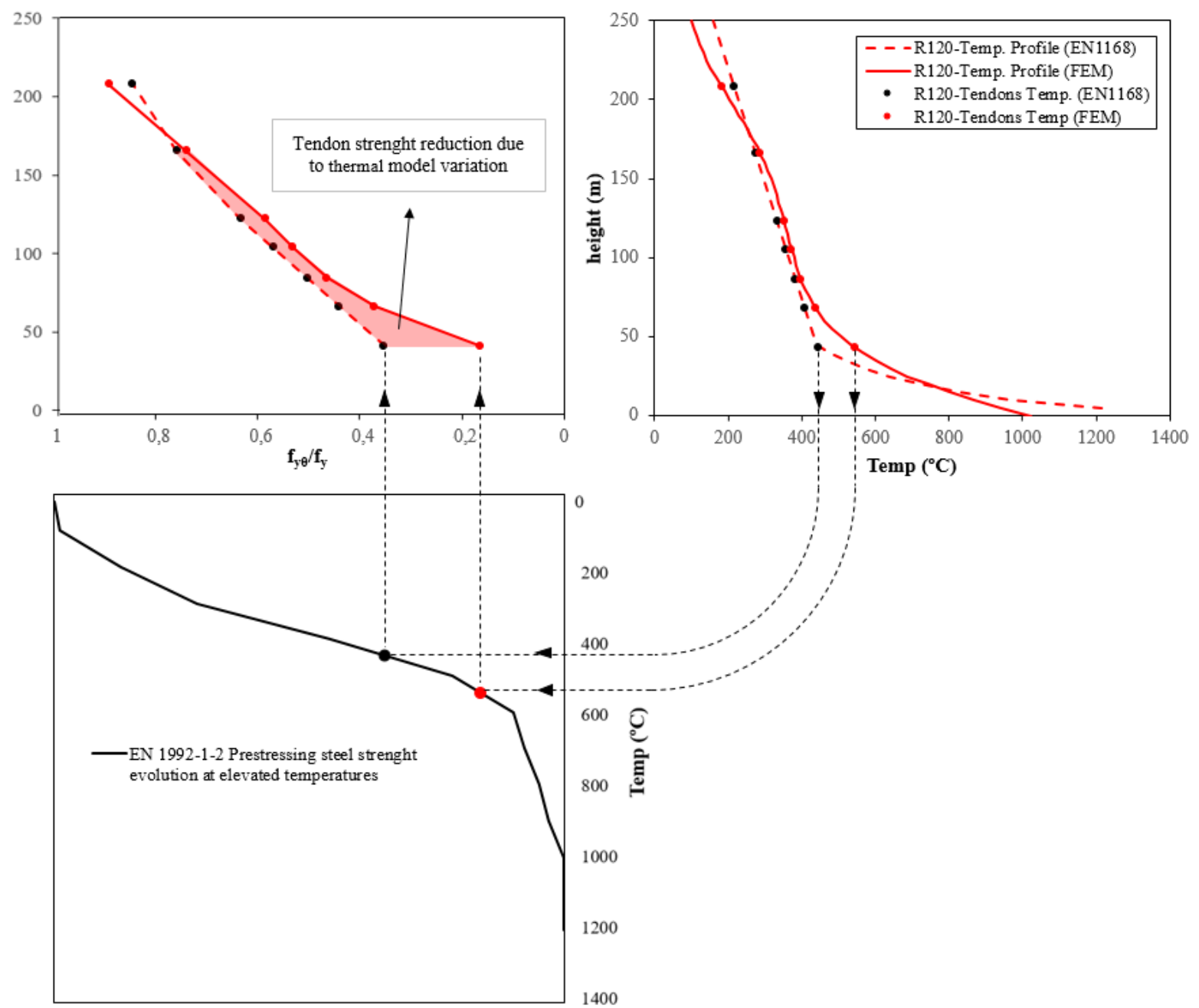

Figure 12. Tendon strength reduction due to thermal model variation 


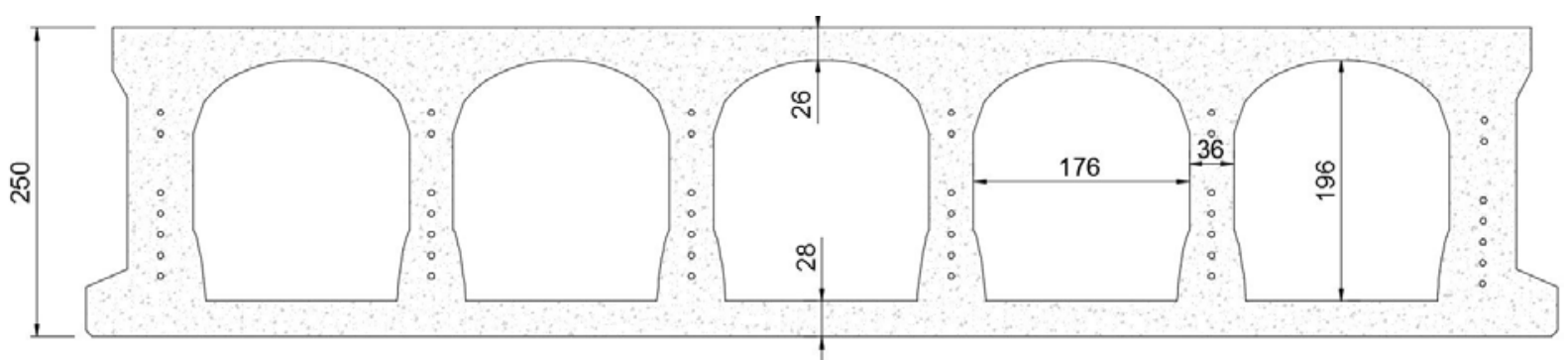

Figure 13. Optimal design R120 using FE thermal model 
Table 1. Model variables

\begin{tabular}{|c|c|c|c|}
\hline \multicolumn{5}{|c|}{ Cross-section geometry } \\
\hline$h$ & Hollow core slab height & $c_{1}$ & Bottom void height \\
\hline$b$ & Hollow core slab width & $d$ & Bottom void plateau \\
\hline$h_{0}$ & Concrete topping height & $a_{2}$ & Top void width \\
\hline$n$ & Number of voids & $a_{1}$ & Bottom void width \\
\hline$h_{2}$ & Top flange thickness & $d_{2}$ & Top curve centre ecc. \\
\hline$h_{1}$ & Bottom flange thickness & $k_{1}$ & Bottom curve degree \\
\hline$h_{w}$ & Web height & $k_{2}$ & Top curve degree \\
\hline$c_{2}$ & Top void height & $b_{w}$ & Web thickness \\
\hline$(\mathbf{q})$ & Lateral joint geometry & & Reinforcement geometry \\
\hline \multicolumn{5}{|c|}{ Material and mechanics } \\
\hline$y_{i}$ & Reinforcement position array & $n_{i j}$ & Reinforcement matrix \\
\hline$\phi_{i}$ & Reinforcement diameter array & & \\
\hline \multicolumn{5}{|c|}{ Tensile strength } & $\sigma_{p, m a x}$ & Maximum stress applied to the tendon \\
\hline$f_{c k}$ & Concrete strength & \\
\hline$f_{p, k}$ & \multicolumn{5}{|c|}{} \\
\hline
\end{tabular}


Table 2. Unit prices considered

\begin{tabular}{|l|l|l|}
\hline Unit & Description & Cost $(€)$ \\
\hline $\mathrm{kg}$ & Steel Y1860 for reinforcement & 0.674 \\
\hline $\mathrm{m}^{3}$ & Concrete HP-45 & 281.57 \\
\hline
\end{tabular}


Table 3. Hollow core slab design situations during life cycle

\begin{tabular}{|l|}
\hline Transient design situations \\
\hline SLS during transfer of prestress \\
\hline ULS during transfer of prestress \\
\hline SLS during floor erection \\
\hline Persistent design situation \\
\hline ULS Bending \\
\hline ULS Shear \\
\hline SLS Deflection \\
\hline SLS Crack control \\
\hline Accidental design situation \\
\hline ULS Bending in fire \\
\hline ULS Shear in fire \\
\hline
\end{tabular}


Table 4. Optimization results

\begin{tabular}{|c|c|c|c|c|}
\hline 10.1 & $\begin{array}{c}\text { Circular voids } \\
\text { R60 (pattern) }\end{array}$ & $\begin{array}{c}\text { Circular voids } \\
\text { R120(pattern) }\end{array}$ & OPT. R60 & OPT. R120 \\
\hline $\begin{array}{c}\text { Cross-section area } \\
\left.\text { A (mm }{ }^{2}\right)\end{array}$ & 165941 & 165941 & $\begin{array}{c}125670 \\
(-24 \%)\end{array}$ & $\begin{array}{c}134639 \\
(-19 \%)\end{array}$ \\
\hline $\begin{array}{c}\text { Upper flange thickness } \\
\mathrm{h}_{2}(\mathrm{~mm})\end{array}$ & 36 & 36 & 26 & 26 \\
\hline $\begin{array}{c}\text { Lower flange thickness } \\
\mathrm{h}_{1}(\mathrm{~mm})\end{array}$ & 37 & 37 & 26 & 27 \\
\hline $\begin{array}{c}\text { Web thickness } \\
\mathrm{b}_{\mathrm{w}}(\mathrm{mm})\end{array}$ & 36 & 36 & 36 & 36 \\
\hline
\end{tabular}


Table 5. Thermal model analysis

\begin{tabular}{|c|c|c|c|c|c|}
\hline \multicolumn{7}{|c|}{ Thermal model analysis } \\
\hline Thermal model & $\begin{array}{c}\text { Optimal design cross- } \\
\text { section } \\
A_{b}\left(\mathrm{~mm}^{2}\right)\end{array}$ & $\begin{array}{c}A_{b}\left(\mathrm{~mm}^{2}\right) \\
\text { Variation }\end{array}$ & $\begin{array}{c}\mathrm{h}_{2} \\
(\mathrm{~mm})\end{array}$ & $\begin{array}{c}\mathrm{h}_{1} \\
(\mathrm{~mm})\end{array}$ & $\begin{array}{c}\mathrm{b}_{\mathrm{w}} \\
(\mathrm{mm})\end{array}$ \\
\hline EN 1168 Annex G & 134639 & - & 26 & 27 & 36 \\
\hline Advanced FE model & 131612 & $-2.2 \%$ & 26 & 28 & 36 \\
\hline
\end{tabular}


Table 6. Sensitivity analysis

\begin{tabular}{|c|c|c|c|c|c|}
\hline \multicolumn{6}{|c|}{ Price ratio analysis } \\
\hline $\begin{array}{l}\text { Price ratio } \\
\left(\mathrm{C}_{\mathrm{s}} / \mathrm{C}_{\mathrm{c}}\right)\end{array}$ & $\begin{array}{c}\text { Optimal design cross- } \\
\text { section } \\
A_{b}\left(\mathrm{~mm}^{2}\right)\end{array}$ & $\begin{array}{l}A_{b}\left(\mathrm{~mm}^{2}\right) \\
\text { Variation }\end{array}$ & $\begin{array}{c}\mathrm{h}_{2} \\
(\mathrm{~mm})\end{array}$ & $\begin{array}{c}\mathrm{h}_{1} \\
(\mathrm{~mm})\end{array}$ & $\begin{array}{c}\mathrm{b}_{\mathrm{w}} \\
(\mathrm{mm})\end{array}$ \\
\hline 18.8 (initial) & 134639 & - & 26 & 27 & 36 \\
\hline $20.7(+10 \%)$ & 132889 & $-1.3 \%$ & 26 & 27 & 36 \\
\hline $16.9(-10 \%)$ & 133562 & $-0.8 \%$ & 26 & 27 & 36 \\
\hline \multicolumn{6}{|c|}{ Concrete strength analysis } \\
\hline $\begin{array}{l}\text { Concrete strength } \\
\qquad \mathrm{f}_{\mathrm{ck}}\end{array}$ & $\begin{array}{c}\text { Optimal design cross- } \\
\text { section } \\
A_{b}\left(\mathrm{~mm}^{2}\right)\end{array}$ & $\begin{array}{l}A_{b}\left(m m^{2}\right) \\
\text { Variation }\end{array}$ & $\begin{array}{c}\mathrm{h}_{2} \\
(\mathrm{~mm})\end{array}$ & $\begin{array}{c}\mathrm{h}_{1} \\
(\mathrm{~mm})\end{array}$ & $\begin{array}{c}\mathrm{b}_{\mathrm{w}} \\
(\mathrm{mm})\end{array}$ \\
\hline 45 (initial) & 134639 & - & 26 & 27 & 36 \\
\hline 35 & 136066 & $+1.06 \%$ & 26 & 27 & 36 \\
\hline 40 & 135716 & $+0.8 \%$ & 26 & 27 & 36 \\
\hline 50 & 138571 & $-1.63 \%$ & 26 & 27 & 36 \\
\hline \multicolumn{6}{|c|}{ Reinforcement system analysis } \\
\hline Reinforcement & $\begin{array}{c}\text { Optimal design cross- } \\
\text { section } \\
A_{b}\left(\mathrm{~mm}^{2}\right) \\
\end{array}$ & $\begin{array}{l}A_{b}\left(\mathrm{~mm}^{2}\right) \\
\text { Variation }\end{array}$ & $\begin{array}{c}\mathrm{h}_{2} \\
(\mathrm{~mm})\end{array}$ & $\begin{array}{c}\mathrm{h}_{1} \\
(\mathrm{~mm})\end{array}$ & $\begin{array}{c}\mathrm{b}_{\mathrm{w}} \\
(\mathrm{mm})\end{array}$ \\
\hline Y 1860 C (wire $\phi 5)$ & 134639 & - & 26 & 27 & 36 \\
\hline Y 1860 S7 (strand 3/8'’) & 133944 & $-1.5 \%$ & 26 & 26 & 37 \\
\hline
\end{tabular}

